This document is the accepted manuscript version of the following article: Layadi, A., Kesse1, B., Yan, W., Romio, M., Spencer, N. D., Zenobi-Wong, M., ... Benetti, E. M. (2020). Oxygen tolerant and cytocompatible iron(0)-mediated ATRP enables the controlled growth of polymer brushes from mammalian cel1 cultures. Journal of the American chemical Society, 142(6), 3158-3164. https://doi.org/10.1021/jacs.9b12974

\title{
Oxygen Tolerant and Cytocompatible Iron(0)-Mediated ATRP Enables the Controlled Growth of Polymer Brushes from Mammalian Cell Cultures
}

\author{
Amine Layadi, ${ }^{\ddagger}$ Benjamin Kessel, ${ }^{\dagger}$ Wenqing Yan, ${ }^{\ddagger}$ Matteo Romio, ${ }^{\ddagger}{ }^{\ddagger}$ Nicholas D. Spencer, ${ }^{\ddagger}$ Marcy \\ Zenobi-Wong, ${ }^{\dagger}$ Krzysztof Matyjaszewski, ${ }^{\#}$ and Edmondo M. Benetti ${ }^{*, \neq, \sharp}$
}

‡ Laboratory for Surface Science and Technology, Department of Materials, ETH Zürich; Vladimir-Prelog-Weg 5, 8093 Zürich,

† Tissue Engineering + Biofabrication Laboratory, Department of Health Sciences and Technology, ETH Zürich, 8093 Zürich, Switzerland

\# Department of Chemistry, Carnegie Mellon University, 440o Fifth Avenue, Pittsburgh, PA 15213, USA.

¥ Biointerfaces, Swiss Federal Laboratories for Materials Science and Technology (Empa), Lerchenfeldstrasse 5, CH9014, St. Gallen, Switzerland

KEYWORDS: polymer brushes; surface functionalization; biointerfaces; surface-initiated polymerization; antifouling

\begin{abstract}
The use of zerovalent iron $\left(\mathrm{Fe}^{\circ}\right)$-coated plates, which act both as a source of catalyst and as a reducing agent during surface-initiated atom transfer radical polymerization (SI-ATRP), enables the controlled growth of a wide range of polymer brushes under ambient conditions, and utilizing either organic or aqueous reaction media. Thanks to its cytocompatibility, $\mathrm{Fe}^{\circ} \mathrm{SI}-\mathrm{ATRP}$ can be applied within cell cultures, providing a tool that can broadly and dynamically modify the substrate's affinity towards cells, without influencing their viability. Upon systematically assessing the application of Fe-based catalytic systems in the controlled grafting of polymers, Fe ${ }^{\circ}$ SI-ATRP emerges as an extremely versatile technique that could be applied to tune the physicochemical properties of cell's microenvironments on biomaterials or within tissue engineering constructs.
\end{abstract}

\section{INTRODUCTION}

Surface-modification strategies involving the controlled growth of polymer brushes by exploiting reversible deactivation radical polymerizations (RDRP) that are tolerant to ambient conditions have been a subject of increasing interest in the materials-science community. ${ }^{1}$ The most prominent examples of such processes have involved the application of oxygen scavengers, in the form of photosensitizers, ${ }^{2,3}$ reducing agents, 4 enzymes, ${ }^{5}$ or zerovalent metal surfaces. ${ }^{6-13}$

While the evolution of oxygen-tolerant, surface-initiated RDRP (SI-RDRP) is paving the way for the translation of "grafted-from" polymers from fundamental studies into technology, the development of controlled polymerizations that are additionally compatible with physiological environments would substantially broaden the applicability of SI-RDRP in materials design. In particular, an RDRP process capable of modifying the physicochemical properties of cellular microenvironments through polymer grafting, without altering cell viability, would allow one to adjust the biological affinity of scaffolds towards a particular cell type during culturing, or alternatively to tune the presentation of biochemical cues triggering a defined cell behavior. More generally, the controlled growth of polymer brushes from cell-loaded supports would enable the fabrication of active biomaterials, capable of re-shaping themselves in a dynamic fashion following biocompatible processes.

Focusing on surface-initiated atom transfer radical polymerization (SI-ATRP), the most widely applied SIRDRP method, we demonstrate here that the application of $\mathrm{Fe}^{\mathrm{o}}$ plates, acting as a source of both biocompatible catalyst and reducing agent, can enable the controlled, rapid growth of polymer brushes within organic as well as in aqueous and cell-culture media.

While introducing and systematically assessing the use of Fe-based catalytic systems in the fabrication of polymer 
brushes, ${ }^{14}$ we show that $\mathrm{Fe}^{\mathrm{o}}$-mediated SI-ATRP (Fe ${ }^{\circ}$ SIATRP) can be performed in the presence of primary articular chondrocytes (ACs) that had been previously cultured on initiator-bearing substrates, generating in situ polymer brushes that substantially alter the settlement of cells without affecting their viability.

\section{RESULTS AND DISCUSSION}

When a monomer and ligand (L) mixture is sandwiched between a $\mathrm{Fe}^{\mathrm{o}}$-coated plate and an ATRP-bearing substrate, the metallic surface rapidly consumes oxygen through the formation of $\mathrm{Fe}_{\mathrm{x}} \mathrm{O}_{\mathrm{y}}$ species, which act as a source of $\mathrm{Fe}^{\mathrm{II}} / \mathrm{Fe}^{\mathrm{III}}$ catalysts, diffusing towards the initiating sites (Figure 1). The growth of polymer brushes then proceeds according to the ATRP equilibrium, and can be efficiently performed without the need for prior deoxygenation of monomer mixtures, or an inert atmosphere.

To illustrate the mechanism of $\mathrm{Fe}^{\circ}$ SI-ATRP and its main features, the synthesis of polymer brushes in organic solvents was first examined. Similarly to what was previously reported in the case of $\mathrm{Cu}^{\circ}$-mediated SI-ATRP, ${ }^{10}$ in the absence of externally added deactivator $\left(\mathrm{Fe}^{\mathrm{III}} \mathrm{Br}_{3}\right)$ the growth of poly(methyl methacrylate) (PMMA) brushes using anisole as solvent and $20 \mathrm{mM}$ of weakly coordinating halide ligands (in the form of tetra-n-butylammonium bromide, $\mathrm{TBABr})^{15^{-17}}$ proceeded slowly, reaching just a few nm of dry thickness in several hours of reaction (Figure 2a), as measured ex situ by variable-angle spectroscopic ellipsometry (VASE). In contrast, when $10 \mathrm{mM} \mathrm{Fe}^{\mathrm{III}} \mathrm{Br}_{3}$ was added to the mixture, the polymerization proceeded rapidly, leading to a progressive growth of PMMA brushes, which reached $\sim 20 \mathrm{~nm}$ after 5 hours of reaction. It is important to emphasize that an excess of $\mathrm{TBABr}$ with respect to $\mathrm{Fe}^{\mathrm{III}} \mathrm{Br}_{3}$ was necessary to guarantee the complete dissolution of Fe species, especially in 50:50 anisole:MMA mixtures $(\mathrm{v} / \mathrm{v})$, where their solubility in the absence of ligand would be limited. ${ }^{15}$

In both these cases, an induction time necessary to oxygen consumption was never observed, suggesting that oxidation of $\mathrm{Fe}^{\mathrm{o}}$ surface quickly takes place just at the very early stages of the reaction.

An analogous result was obtained in the case of $\mathrm{Fe}^{\circ} \mathrm{SI}-$ ATRP of oligo(ethylene glycol) methacrylate (OEGMA) performed in $\mathrm{N}, \mathrm{N}$-dimethylformamide (DMF), where a comparable amount of $\mathrm{Fe}^{\mathrm{III}} \mathrm{Br}_{3}$ was required to attain a significant growth of POEGMA brushes, reaching nearly 30 $\mathrm{nm}$ of thickness in 5 hours (Figure $2 \mathrm{~b}$ ).

The role played by added $\mathrm{Fe}^{\mathrm{III}} \mathrm{Br}_{3}$ was elucidated while monitoring the variation of POEGMA-brush thickness as a function of $\mathrm{Fe}^{\mathrm{III}} \mathrm{Br}_{3}$ concentration for fixed polymerization times (Figure 2c). The thickness of POEGMA brushes increased with $\left[\mathrm{Fe}^{\mathrm{III}} \mathrm{Br}_{3}\right]$, reaching a maximum between 5 and $10 \mathrm{mM}$. Under these conditions, $\mathrm{Fe}^{\mathrm{III}}$ species acted both as a deactivator, suppressing irreversible termination by radical recombination between growing chains, and contributed to generating $\mathrm{Fe}^{\mathrm{II}}$-based activators through comproportionation with $\mathrm{Fe}^{\mathrm{o}}$ (Figure 1 ), in this way accelerating the grafting process. ${ }^{15}$
A further addition of $\mathrm{Fe}^{\mathrm{III}} \mathrm{Br}_{3}$ beyond $10 \mathrm{mM}$ led to a decrease in brush thickness, suggesting a significant deactivation and a simultaneous slowing down of the polymerization.

It is important to emphasize that the balance between the above-mentioned effects determined the position of the maximum of polymer-brush thickness as a function of $\left[\mathrm{Fe}^{\mathrm{III}} \mathrm{Br}_{3}\right]$, which might shift during the progression of the grafting process. An increment in the content of activators through comproportionation led to an increase in brushgrowth rate, especially during the early stages of polymerization. Simultaneously, an increase in deactivation by added $\mathrm{Fe}^{\mathrm{III}}$ species slowed down the grafting process, although it additionally suppressed irreversible termination by radical recombination between propagating grafts, which is especially relevant after relatively long reaction times (for more flexible, highmolecular-weight grafted chains) ${ }^{18}$

$\mathrm{Fe}^{\mathrm{o}}$ SI-ATRP was subsequently investigated in aqueous environments, and using ethylenediaminetetraacetic acid (EDTA) as a ligand. EDTA strongly binds Fe species to form

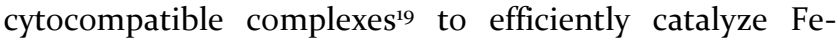
based ATRP in solution and heterogeneous systems, as previously demonstrated..$^{20,21}$

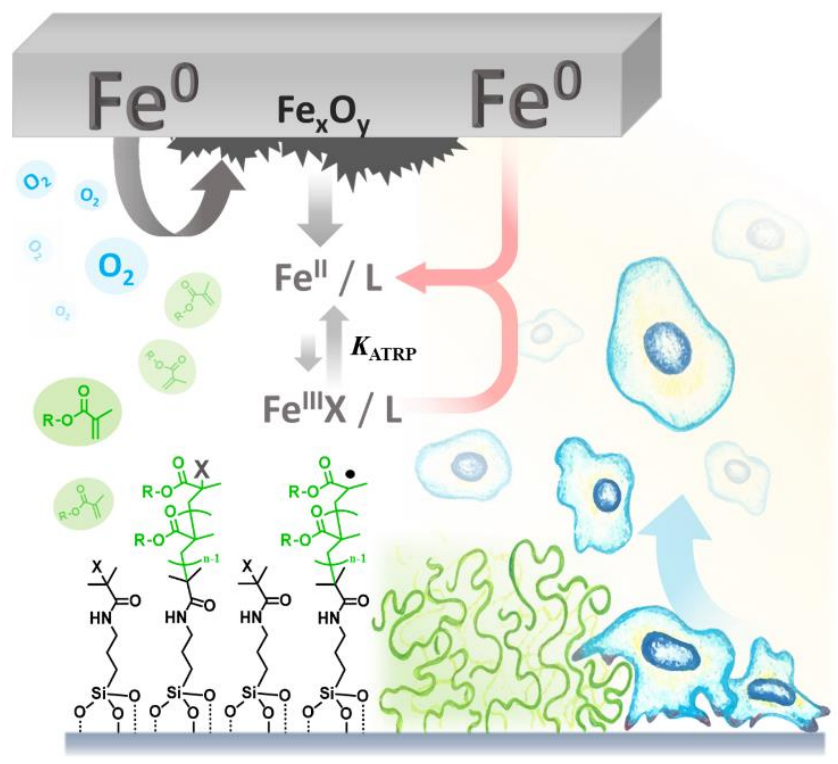

Figure 1. Schematic depicting the mechanism of $\mathrm{Fe}^{\circ}$ SI-ATRP.

In the exemplary case of $\mathrm{Fe}^{\mathrm{o}}$ SI-ATRP of OEGMA performed in $50 \%$ water mixtures $(\mathrm{v} / \mathrm{v})$, the growth of brushes followed much faster kinetics compared to those recorded in organic media, as expected from the significantly larger ATRP equilibrium constant $\left(K_{\mathrm{ATRP}}\right)$ that is characteristic for aqueous systems. ${ }^{22-24}$ More than 150 nm-thick POEGMA brushes could be grown in just one hour of polymerization when 2.5-5 $\mathrm{mM} \mathrm{Fe}^{\mathrm{III}} \mathrm{Cl}_{3}$-EDTA were added to the aqueous reaction mixture (Figure $2 \mathrm{~d}$ and Figure $\mathrm{S}_{1}$ ), whereas just $\sim 5 \mathrm{~nm}$-thick brushes were grafted after the same time using DMF as solvent, and no appreciable brush growth could be recorded in anisole.

The presence of $5 \mathrm{mM}$ EDTA alone enabled the synthesis of significantly thinner films, which initially grew following 

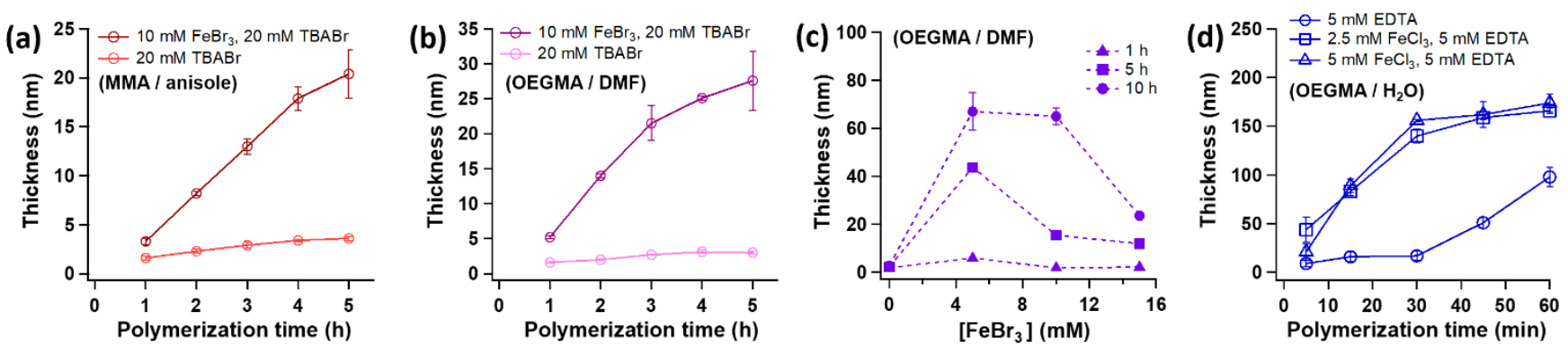

Figure 2. (a) Dry thickness of PMMA brushes measured ex situ by VASE during $\mathrm{Fe}^{\circ}$ SI-ATRP of MMA performed in $50 \%$ (v/v) anisole solutions with $20 \mathrm{mM}$ TBABr and with or without $10 \mathrm{mM} \mathrm{Fe}^{\mathrm{III}} \mathrm{Br}_{3}$. (b) $\mathrm{Fe}^{\circ}$ SI-ATRP of OEGMA performed in $50 \%$ (v/v) DMF solutions with $20 \mathrm{mM}$ TBABr and with or without $10 \mathrm{mM} \mathrm{Fe}^{\mathrm{III}} \mathrm{Br}_{3}$. (c) Variation of POEGMA-brush thickness measured by VASE, as a function of $\mathrm{Fe}^{\mathrm{IIII}} \mathrm{Br}_{3}$ concentration, while keeping the concentration of TBABr fixed at $20 \mathrm{mM}$. (d) Dry thickness of POEGMA brushes measured by VASE during Fe ${ }^{\circ}$ SI-ATRP of OEGMA performed in $50 \%(\mathrm{v} / \mathrm{v})$ water solutions containing $5 \mathrm{mM}$ EDTA, $10 \mathrm{mM} \mathrm{NaCl}$ and variable concentrations of $\mathrm{Fe}^{\mathrm{III}} \mathrm{Cl}_{3}$.

relatively slow kinetics. This was presumably due to the time required by $\mathrm{Fe}^{\mathrm{II}} / \mathrm{Fe}^{\mathrm{III}}$-EDTA adducts to diffuse from the Fe plate to the initiator-bearing substrate. ${ }^{10}$

Using $5 \mathrm{mM} \mathrm{Fe}^{\mathrm{III}} \mathrm{Cl}_{3}$-EDTA, a range of bio-relevant polymer brushes could be grafted by polymerizing 2methacryloyloxyethyl phosphorylcholine (MPC, $3 \mathrm{M}$ ), Nisopropylacrylamide (NIPAM, 2 M) and 2-hydroxyethyl methacrylate (HEMA, $4 \mathrm{M}$ ), obtaining extremely thick PMPC $(250 \pm 7 \mathrm{~nm})$, PNIPAM $(219 \pm 12 \mathrm{~nm})$ and PHEMA $(137 \pm 5 \mathrm{~nm})$ films just after $45 \mathrm{~min}$ of reaction (Figure $3 \mathrm{a}$ ). Aqueous $\mathrm{Fe}^{\circ}$ SI-ATRP could be further applied for growing similar brush films from large substrates, as demonstrated in the case of PMPC brushes, which could be grown from 4 -inch silicon wafers, forming $\sim 200 \mathrm{~nm}$-thick films with homogeneous thickness and morphology after $30 \mathrm{~min}$ of polymerization (Figure $3 \mathrm{c}$ and Figure $\mathrm{S}_{3}$ ). Detachment of PMPC grafts ${ }^{25-27}$ enabled their characterization by sizeexclusion chromatography (SEC), yielding a $M_{\mathrm{n}}$ of $600 \mathrm{kDa}$ and a $Ð$ of 1.34 (corresponding to a surface coverage of 0.23 chains $\left.\mathrm{nm}^{-2}\right),{ }^{28}$ and suggesting a well-controlled polymerization process (inset in Figure $3 \mathrm{C}$ ).

In order to test the applicability of $\mathrm{Fe}^{\circ} \mathrm{SI}-\mathrm{ATRP}$ within cell cultures, we subsequently analyzed the growth of PMPC brushes using Dulbecco's modified Eagle's medium (DMEM) as a solvent, and simultaneously tested the cytocompatibility of the polymerization conditions employed towards ACs.

PMPC brushes are especially relevant in the design of biointerfaces due to their biocompatibility and inertness towards unspecific protein and cell contamination. ${ }^{29-31}$ As a result of their pronounced hydration, the growth of PMPC grafts from substrates previously cultured with cells would directly translate into an evident variation in the strength of cell attachment, leading to the progressive detachment of ACs when the thickness and density of the underlying brushes reached sufficiently high values. ${ }^{32}$

$\mathrm{Fe}^{\circ}$ SI-ATRP of a diluted, o.3 M MPC solution in DMEM using $5 \mathrm{mM} \mathrm{Fe}{ }^{\mathrm{III}} \mathrm{Cl}_{3}$-EDTA resulted in a slow but notable growth of brushes, which reached $\sim 15 \mathrm{~nm}$ after 60 min of reaction (Figure 3b). Relevantly, the slower polymer-brush thickening rate compared to those recorded using pure water as solvent (Figure 3a) was mainly due to the relatively low monomer concentration employed (Figure S4). When ACs were cultured for $24 \mathrm{~h}$ on tissue culture polystyrene wells (TCPS), and subsequently exposed for 1
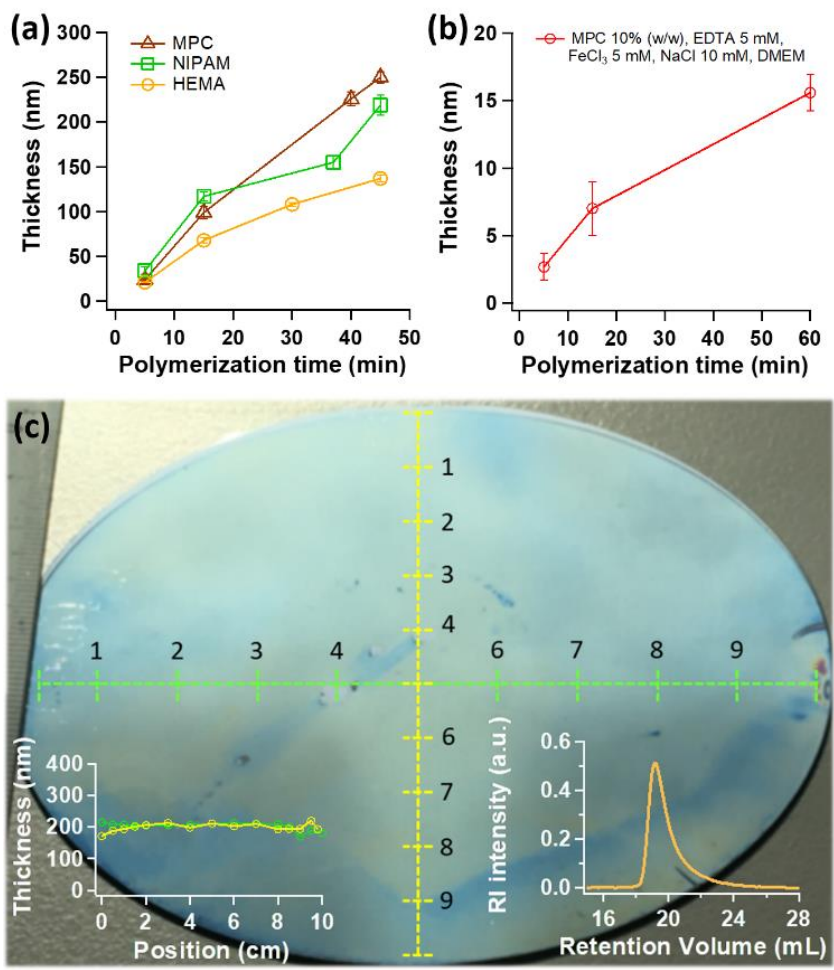

Figure 3. (a) Evolution of brush thickness measured by VASE during $\mathrm{Fe}^{\circ}$ SI-ATRP of MPC, NIPAM and HEMA. (b) PMPC-brush thickness measured by VASE during $\mathrm{Fe}^{\circ}$ SI-ATRP performed in o.3 M MPC DMEM solutions. (c) PMPC brushes grafted from an entire, 4-inch silicon wafer by $\mathrm{Fe}^{\circ}$ SI-ATRP. The brush thickness measured by VASE across the surface is reported in the inset. A SEC trace from detached PMPC brushes is also shown.

hour to a 0.3 M DMEM solution of MPC, the cell density did not significantly vary (from $45000 \pm 12700$ to $43200 \pm$ 7500 cells $\mathrm{cm}^{-2}, \mathrm{p}=0.99$ ) (Figure $4 \mathrm{a}$ ), while cell viability was higher than $90 \%$ just after exposure to monomer solution, and increased to $98 \%$ after $48 \mathrm{~h}$ of additional culture in standard DMEM-based medium (Figure $4 \mathrm{~b}$ ). Incubation for $1 \mathrm{~h}$ in $5 \mathrm{mM}$ DMEM solution of $\mathrm{Fe}^{\mathrm{III}} \mathrm{Cl}_{3}$ EDTA resulted in a significant reduction in cell density $\left(17500 \pm 5300\right.$ cells $\left.\mathrm{cm}^{-2}\right)$ both with respect to the control ( $\mathrm{p}$ $=0.03)$, and compared to the substrates treated with just 0.3 M MPC $(\mathrm{p}=0.05)$ (Figure 4a).

Partial cell detachment after treatment with $\mathrm{Fe}^{\mathrm{III}} \mathrm{Cl}_{3}$ EDTA was presumably due to complexation of $\mathrm{Ca}^{\mathrm{II}}$ within membrane proteins by residual amounts of unbound ligand, which influenced integrin-mediated ACs 

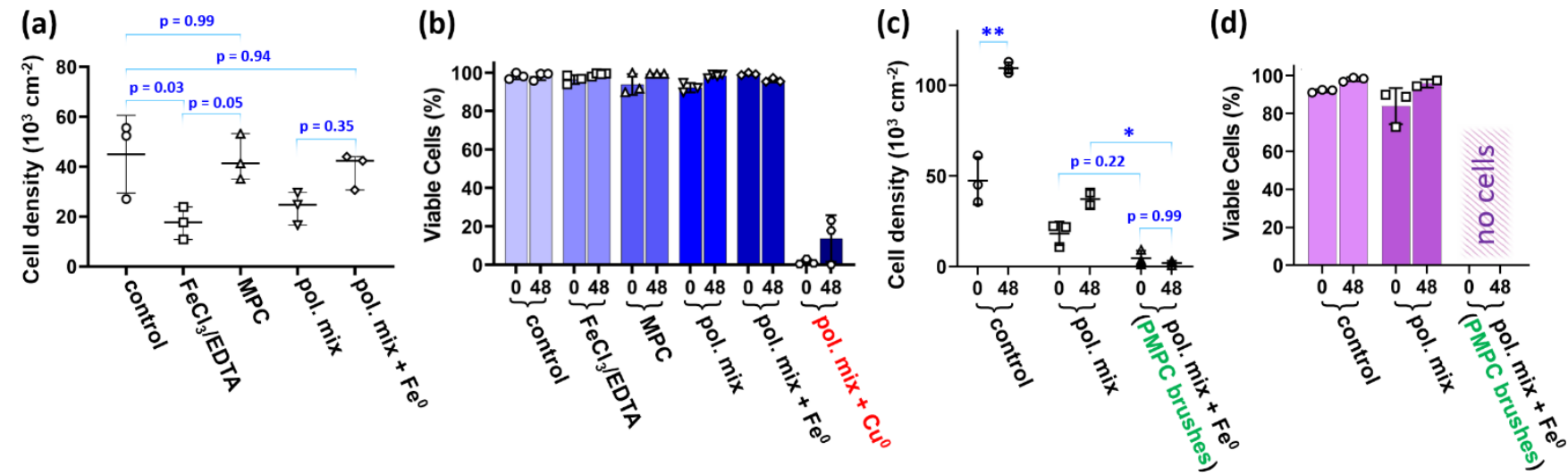

Figure 4. (a) Density of ACs estimated after $24 \mathrm{~h}$ of culture on TCPS, followed by exposure for $1 \mathrm{~h}$ to different media, including DMEM (indicated as control), $5 \mathrm{mM}$ EDTA with $5 \mathrm{mM} \mathrm{Fe}{ }^{\mathrm{III}} \mathrm{Cl}_{3}$ in DMEM (indicated as EDTA/ $\mathrm{FeCl}_{3}$ ), $0.3 \mathrm{M}$ MPC in DMEM (indicated as MPC), o.3 M MPC with $5 \mathrm{mM} \mathrm{Fe}^{\mathrm{III}} \mathrm{Cl}_{3}$-EDTA and $10 \mathrm{mM} \mathrm{NaCl}$ (indicated as pol. mix), and the latter mixture covered by a $\mathrm{Fe}^{\circ} \mathrm{plate}$ (indicated as pol. mix + $\mathrm{Fe}^{\mathrm{o}}$ ). Statistical analysis was conducted by one-way analysis of variance (ANOVA) with a Dunnett's post-hoc-Test; * indicates $\mathrm{p}<0.05$. (b) Cell viability estimated by live-dead staining on AC cultures subjected for $1 \mathrm{~h}$ to the solutions indicated above, and a polymerization mixture including 0.3 M MPC, $5 \mathrm{mM} \mathrm{CuBr}{ }_{2}$-tris(2-pyridylmethyl)amine (TPMA), $10 \mathrm{mM} \mathrm{NaBr}$, and covered with a $\mathrm{Cu}^{\circ}$ plate. ${ }^{12}$ (c) Density of ACs estimated after $24 \mathrm{~h}$ of culture on ATRP initiator-functionalized $\mathrm{SiO}_{\mathrm{x}}$ substrates and subjected to $1 \mathrm{~h}$ of exposure to different mixtures, and after the growth of PMPC brushes (pol. mix $+\mathrm{Fe}^{\circ}$ ). Statistical analysis was conducted by two-way ANOVA with Tukey's multiple comparisons test; * indicates $\mathrm{p}<0.05,{ }^{* *}$ indicates $\mathrm{p}<0.001$. (d) Cell viability estimated by live-dead staining for $\mathrm{AC}$ cultures on $\mathrm{ATRP}^{\text {initiator-bearing SiO }}{ }_{x}$ surfaces subjected for $1 \mathrm{~h}$ to different mixtures.

adhesion. ${ }^{33,34}$ A comparable result was observed when ACs were incubated in the complete polymerization mixture (o.3 M MPC + $5 \mathrm{mM} \mathrm{Fe}{ }^{\mathrm{III}} \mathrm{Cl}_{3}$-EDTA), while a slight increment in cell density was recorded when $\mathrm{Fe}^{\mathrm{o}}$-coated plates were additionally placed in contact with the cultures, reproducing the reaction setup typically employed during $\mathrm{Fe}^{\circ}$ SI-ATRP of MPC ( $\mathrm{p}=0.35$, Figure $\left.4 \mathrm{a}\right)$. In these samples, additional $\mathrm{Fe}^{\mathrm{II}} / \mathrm{Fe}^{\mathrm{III}}$ species leaking from the iron plates were probably complexed by the residual, unbound EDTA, finally preventing complexation of $\mathrm{Ca}^{\mathrm{II}}$ from cell proteins.

It is important to emphasize that, despite the observed variations in cell density after exposure to the different monomer/ligand mixtures, AC viability was in all cases higher than $90 \%$, and comparable to that measured for the controls. Even when the oxygen dissolved in the culture media was rapidly consumed by exposure to $\mathrm{Fe}^{\circ}$, the tolerance of chondrocytes towards anaerobic conditions 35 guaranteed their remarkably high viability, while AC densities were similar to those recorded for the control samples $\left(39000 \pm 6000\right.$ and $45000 \pm 12700$ cells $\mathrm{cm}^{-2}$, respectively, in Figure $4 \mathrm{a}, \mathrm{p}=0.94)$. The cytocompatibility of the polymerization mixtures employed during $\mathrm{Fe}^{\circ}$ SIATRP was further highlighted by comparing the viability of ACs exposed to a corresponding $\mathrm{Cu}$-based catalytic system, which was previously reported to enable the rapid growth of polymer brushes by $\mathrm{Cu}^{\circ}$ SI-ATRP. ${ }^{6-13}$ In this latter case, AC viability was nearly o\% after $1 \mathrm{~h}$ of exposure, and increased just to $\sim 10 \%$ following $48 \mathrm{~h}$ of further culture in standard medium (Figure $4 \mathrm{~b}$ and $\mathrm{S}_{5}$ ), confirming the toxicity towards mammalian cells of mixtures typically employed during $\mathrm{Cu}$-based ATRP.

When TCPS substrates were replaced by ATRP-initiatorbearing $\mathrm{SiO}_{\mathrm{x}}$ surfaces, the effect of PMPC brush growth on AC adhesion was analyzed.

Also in these experiments, ACs were initially cultured on the substrates for $24 \mathrm{~h}$, followed by exposure to different mixtures for $\mathrm{h}$, followed by additional $48 \mathrm{~h}$ of culture.
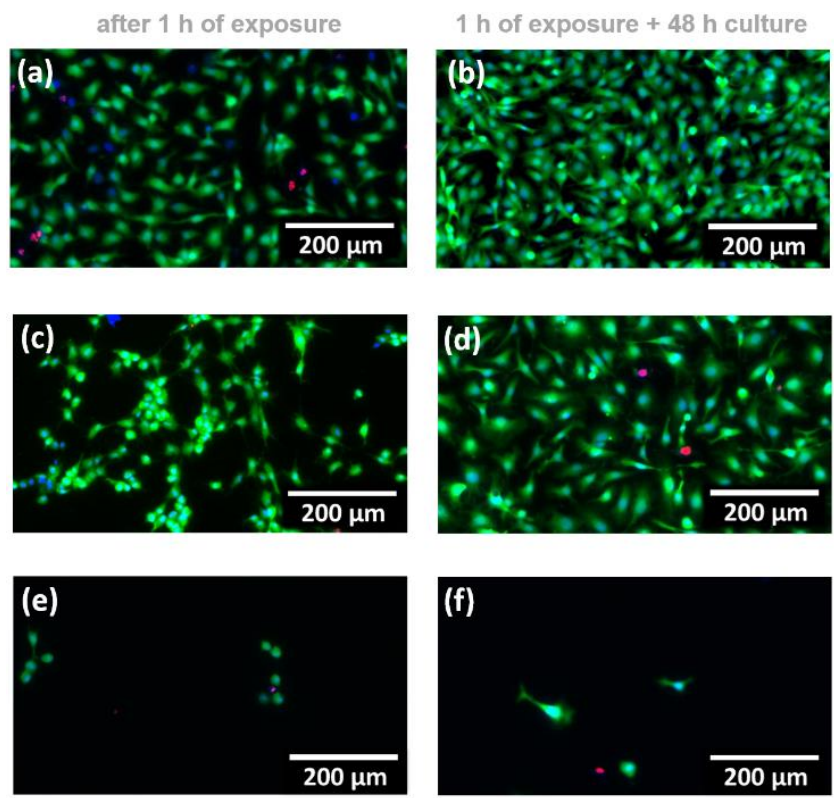

Figure 5. Immunofluorescence micrographs displaying ACs stained with calcein AM (green), Hoechst 33342 (blue), and propidium iodide (red) after $1 \mathrm{~h}$ of exposure to the different polymerization mixtures (a, c, e) and following $48 \mathrm{~h}$ of further culture (b, d, f).

Cell density significantly decreased after $1 \mathrm{~h}$ of exposure to the polymerization mixture (o.3 M MPC, $5 \mathrm{mM} \mathrm{Fe}^{\mathrm{III}} \mathrm{Cl}_{3}$ EDTA) compared to that measured when ACs were simply incubated in DMEM-based medium, from $47400 \pm 11000$ to $18300 \pm 12700$ cells $\mathrm{cm}^{-2}(\mathrm{p}<0.05)$. Nevertheless, cell viability remained relatively high $(83 \pm 15 \%)$. As highlighted in the immunofluorescence micrographs reported in Figure 5c, ACs exhibited a more rounded morphology as a result of partial inhibition of cell-cell and cell-substrate adhesion through $\mathrm{Ca}^{\mathrm{II}}$ complexation by EDTA. However, it is remarkable that following a further $48 \mathrm{~h}$ of culture in standard medium an increment in cell density from $18300 \pm 12700$ to $37300 \pm 6900$ cells cm$~^{-2}(p=$ o.08) was observed, due to AC proliferation, basically attaining cell densities similar to those recorded before 
exposure to the polymerization medium. This result confirmed the cytocompatibility of the polymerization conditions applied during $\mathrm{Fe}^{\circ}$ SI-ATRP. In addition, a wellspread cell morphology was completely recovered (Figure 5d), indicating that ACs strongly adhered to the substrate after an additional $48 \mathrm{~h}$ of culture.

When $\mathrm{Fe}^{\mathrm{o}}$-coated plates were applied together with the polymerization mixtures on AC cultures, the rapid growth of PMPC brushes led to the formation of a highly hydrated, and cell-repellent interface, which substantially weakened AC attachment and lead to a nearly complete detachment of cells $\left(4700 \pm 4300\right.$ cells $\mathrm{cm}^{-2}$, after $1 \mathrm{~h}$ of exposure). Relatively few, rounded cells remained on the substrates, adhering to surface defects where polymer grafting did not occur due to the adventitious, mechanical removal of ATRP initiator, and were surrounded by a uniform film of PMPC brushes, as evidenced by atomic force microscopy (AFM) (Figure 6). Selective deposition of ATRP initiator on just one side of a silicon substrate additionally proved that $\mathrm{Fe}^{\circ}$ SI-ATRP could be easily applied to spatially control the growth of biopassive polymer brushes, and trigger cell detachment specifically on the areas of the substrate where polymer grafting could be initiated (Figure S6).

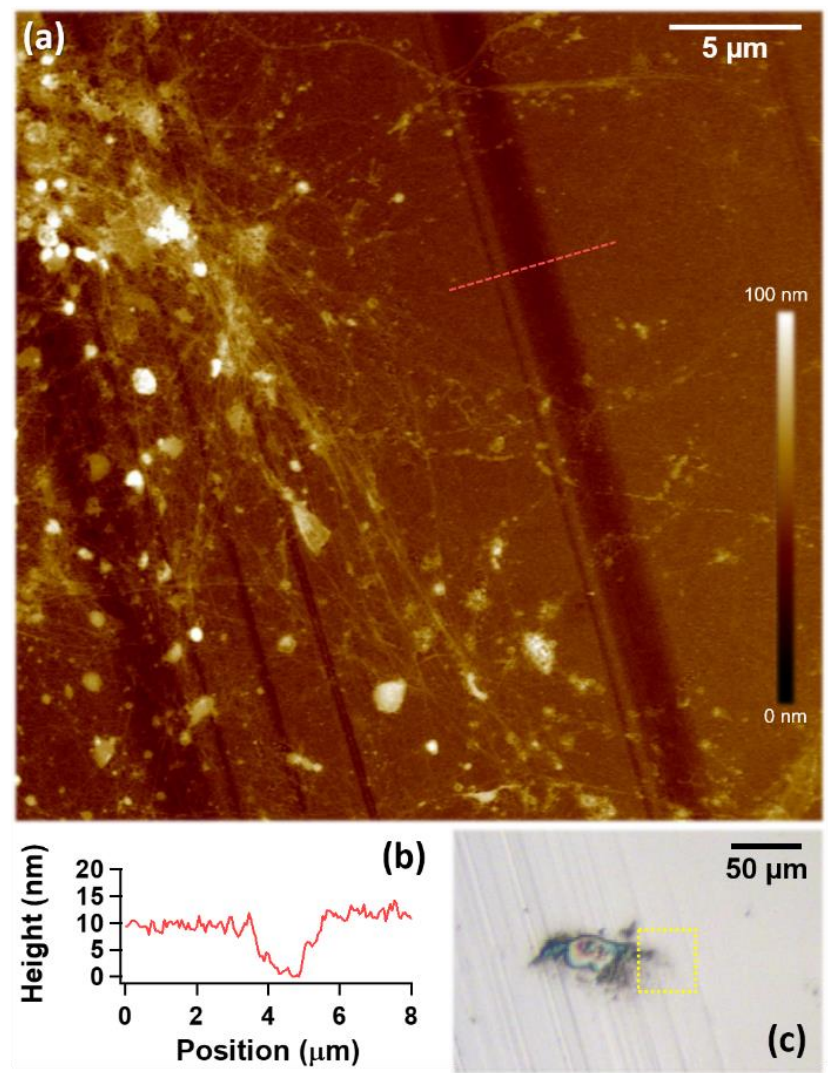

Figure 6. (a) AFM tapping mode micrographs displaying cellular components of ACs extending on surface defects where PMPC brushes did not grow following $\mathrm{Fe}^{\mathrm{o}}$ SI-ATRP, due to mechanical removal of ATRP initiator layer. In (b) a cross section highlighting the height of PMPC brushes around a mechanically scratched area on the substrate is provided. The optical micrograph (c) displays how ACs remained attached on areas where PMPC brushes could not be grown due to the removal of ATRP initiator layer by mechanical scratching.

These results collectively indicated that PMPC-brush growth by $\mathrm{Fe}^{\circ}$ SI-ATRP could be performed from AC cultures, substantially altering the interfacial physicochemical properties of the supporting substrates, and thus strongly influencing cell attachment. The observed release of cells was clearly not due to the polymerization conditions applied during culturing, as confirmed by the tolerance of ACs towards the reaction mixtures, their markedly high viability and tendency to proliferate in such media.

The growth of bio-repellent brushes, mediated by $\mathrm{Fe}^{\circ}$, emerges as the main phenomenon leading to a critical shift in the characteristics of the surrounding environment, to which ACs respond by weakening their affinity towards the substrates, ultimately being released from a surface that is no longer bio-adhesive.

It is noteworthy to mention that ATRP methods were already demonstrated to be applicable within cell cultures while maintaining viable cells. ${ }^{36}$ However, polymer growth was tested in the presence of yeast cells, which are known to be extremely resilient, and which, similarly to bacteria, are protected by strong cell walls and can survive greater stresses than mammalian cells. ${ }^{37}$

\section{CONCLUSIONS}

Due to its tolerance to ambient conditions and scalability, $\mathrm{Fe}^{\circ}$ SI-ATRP emerges as a versatile method to synthesize chemically diverse polymer brushes for a variety of materials formulations. Its highly confined nature enables the generation of uniform brush films over very large areas, without the need of previous deoxygenation of the reaction mixtures or the presence of an inert atmosphere, and by employing just few microliters of monomer/catalyst solutions. These unique features, which are highlighted through a comprehensive analysis of its mechanistic aspects, make $\mathrm{Fe}^{o}$ SI-ATRP a very promising technique for translating SI-RDRP processes into technologically relevant surface fabrications.

Thanks to its cytocompatibility towards mammalian cells, $\mathrm{Fe}^{\circ}$ SI-ATRP could be easily applied to biomaterials and within tissue engineering constructs, dynamically tuning the physicochemical properties of cell microenvironments.

\section{ASSOCIATED CONTENT}

Experimental details and further characterization are included in the Supporting Information. This material is available free of charge via the Internet at http://pubs.acs.org.

\section{AUTHOR INFORMATION}

\section{Corresponding Author}

* Edmondo M. Benetti, Laboratory for Surface Science and Technology, Department of Materials, ETH Zürich, VladimirPrelog-Weg 5, 8093 Zürich; Biointerfaces, Swiss Federal Laboratories for Materials Science and Technology (Empa), Lerchenfeldstrasse 5, CH-9014, St. Gallen, Switzerland. EMail:edmondo.benetti@mat.ethz.ch

\section{Author Contributions}


The manuscript was written through contributions of all authors. All authors have given approval to the final version of the manuscript.

\section{ACKNOWLEDGMENT}

The authors are grateful to Prof. Katharina Maniura (Empa) for the fruitful discussions. This work was financially supported by European Union's Horizon 2020 research and innovation program (grant agreement No 669562), and the Swiss National Science Foundation (SNSF "Ambizione" PZooP2-79o 148156).

\section{REFERENCES}

(1) Yeow, J.; Chapman, R.; Gormley, A. J.; Boyer, C., Up in the air: oxygen tolerance in controlled/living radical polymerisation. Chem. Soc. Rev. 2018, 47 (12), 4357-4387.

(2) Narupai, B.; Page, Z. A.; Treat, N. J.; McGrath, A. J.; Pester, C. W.; Discekici, E. H.; Dolinski, N. D.; Meyers, G. F.; de Alaniz, J. R.; Hawker, C. J., Simultaneous Preparation of Multiple Polymer Brushes under Ambient Conditions using Microliter Volumes. Angew. Chem. Int. Edit. 2o18, 57 (41), 13433-13438.

(3) Li, M.; Fromel, M.; Ranaweera, D.; Rocha, S.; Boyer, C.; Pester, C. W., SI-PET-RAFT: Surface-Initiated Photoinduced Electron Transfer-Reversible Addition-Fragmentation Chain Transfer Polymerization. ACS Macro Lett. 2019, 8, 374-38o. (4) Matyjaszewski, K.; Dong, H. C.; Jakubowski, W.; Pietrasik, J.; Kusumo, A., Grafting from surfaces for "Everyone": ARGET ATRP in the presence of air. Langmuir 2007, 23 (8), 4528-4531.

(5) Navarro, L. A.; Enciso, A. E.; Matyjaszewski, K.; Zauscher, S., Enzymatically Degassed Surface-Initiated Atom Transfer Radical Polymerization with Real-Time Monitoring. J. Am. Chem. Soc. 2019, 141 (7), 3100-3109.

(6) Zhang, T.; Du, Y.; Muller, F.; Amin, I.; Jordan, R., Surfaceinitiated $\mathrm{Cu}(\mathrm{o})$ mediated controlled radical polymerization (SICuCRP) using a copper plate. Polym. Chem. 2o15, 6 (14), 27262733.

(7) Zhang, T.; Du, Y. H.; Kalbacova, J.; Schubel, R.; Rodriguez, R. D.; Chen, T.; Zahn, D. R. T.; Jordan, R., Wafer-scale synthesis of defined polymer brushes under ambient conditions. Polym. Chem. 2015, 6 (47), 8176-8183.

(8) Dehghani, E. S.; Du, Y.; Zhang, T.; Ramakrishna, S. N.; Spencer, N. D.; Jordan, R.; Benetti, E. M., Fabrication and Interfacial Properties of Polymer Brush Gradients by SurfaceInitiated $\mathrm{Cu}(\mathrm{o})$-Mediated Controlled Radical Polymerization. Macromolecules 2017, 50 (6), 2436-2446.

(9) Che, Y. J.; Zhang, T.; Du, Y. H.; Amin, I.; Marschelke, C.; Jordan, R., "On Water" Surface-initiated Polymerization of Hydrophobic Monomers. Angew. Chem. Int. Edit. 2018, 57 (50), 16380-16384.

(10) Fantin, M.; Ramakrishna, S. N.; Yan, J. J.; Yan, W. Q.;

Divandari, M.; Spencer, N. D.; Matyjaszewski, K.; Benetti, E. M., The Role of $\mathrm{Cu}^{\circ}$ in Surface-Initiated Atom Transfer Radical Polymerization: Tuning Catalyst Dissolution for Tailoring Polymer Interfaces. Macromolecules 2018, 51 (17), 6825-6835. (11) Zhang, T.; Benetti, E. M.; Jordan, R., Surface-Initiated Cu(o)Mediated CRP for the Rapid and Controlled Synthesis of Quasi3D Structured Polymer Brushes. ACS Macro Lett. 2019, 8 (2), 145153 .

(12) Yan, W. Q.; Fantin, M.; Spencer, N. D.; Matyjaszewski, K.; Benetti, E. M., Translating Surface-Initiated Atom Transfer Radical Polymerization into Technology: The Mechanism of $\mathrm{Cu}^{{ }^{-}}$ Mediated SI-ATRP under Environmental Conditions. ACS Macro Lett. 2019, 8, 865-870.

(13) Yan, W. Q.; Fantin, M.; Ramakrishna, S.; Spencer, N. D.; Matyjaszewski, K.; Benetti, E. M., Growing Polymer Brushes from a Variety of Substrates under Ambient Conditions by $\mathrm{Cu}^{{ }^{-}-}$ Mediated Surface-Initiated ATRP. ACS Appl. Mater. Interfaces 2019, 11 (30), 27470-27477.
(14) Divandari, M.; Pollard, J.; Dehghani, E.; Bruns, N.; Benetti, E. M., Controlling Enzymatic Polymerization from Surfaces with Switchable Bioaffinity. Biomacromolecules 2017, 18 (12), 42614270.

(15) Wang, Y.; Zhang, Y. Z.; Parker, B.; Matyjaszewski, K., ATRP of MMA with ppm Levels of Iron Catalyst. Macromolecules 2011, 44 (11), 4022-4025.

(16) Wang, Y.; Matyjaszewski, K., ATRP of MMA Catalyzed by $\mathrm{Fe}^{\mathrm{II}} \mathrm{Br}_{2}$ in the Presence of Triflate Anions. Macromolecules 2o11, 44 (6), 1226-1228.

(17) Teodorescu, M.; Gaynor, S. G.; Matyjaszewski, K., Halide anions as ligands in iron-mediated atom transfer radical polymerization. Macromolecules 2000, 33 (7), 2335-2339. (18) Zhou, D. P.; Gao, X.; Wang, W. J.; Zhu, S. P., Termination of Surface Radicals and Kinetic Modeling of ATRP Grafting from Flat Surfaces by Addition of Deactivator. Macromolecules 2012, 45 (3), 1198-1207.

(19) Lanigan, R. S.; Yamarik, T. A., Final report on the safety assessment of EDTA, Calcium Disodium EDTA, diammonium EDTA, Dipotassium EDTA, Disodium EDTA, TEA-EDTA, Tetrasodium EDTA, Tripotassium EDTA, Trisodium EDTA, HEDTA, and Trisodium HEDTA. Int. J. Toxicol. 2002, 21 (5), 95142.

(20) Bergenudd, H.; Jonsson, M.; Nystrom, D.; Malmstrom, E., Heterogeneous iron(II)-chloride mediated radical

polymerization of styrene. J. Mol. Catal. A-Chem. 2009, 306 (1-2), 69-76.

(21) Wang, G. X.; Lu, M.; Wu, H., SET LRP of MMA mediated by $\mathrm{Fe}(\mathrm{o}) /$ EDTA in the presence of air. Polym. Bull. 2012, 69 (4), 417427.

(22) Coullerez, G.; Carlmark, A.; Malmström, E.; Jonsson, M., Understanding Copper-Based Atom-Transfer Radical Polymerization in Aqueous Media. J. Phys. Chem. A 2004, 108, 7129-7131.

(23) Jones, D. M.; Huck, W. T. S., Controlled surface-initiated polymerizations in aqueous media. Adv. Mater. 2001, 13 (16), 1256-1259.

(24) Konkolewicz, D.; Krys, P.; Gois, J. R.; Mendonca, P. V.; Zhong, M. J.; Wang, Y.; Gennaro, A.; Isse, A. A.; Fantin, M.; Matyjaszewski, K., Aqueous RDRP in the Presence of Cu-o: The Exceptional Activity of Cu-I Confirms the SARA ATRP Mechanism. Macromolecules 2014, 47 (2), 560-570.

(25) Patil, R. R.; Turgman-Cohen, S.; Srogl, J.; Kiserow, D.; Genzer, J., Direct Measurement of Molecular Weight and Grafting Density by Controlled and Quantitative Degrafting of Surface-Anchored Poly(methyl methacrylate). ACS Macro Lett. 2015, 4 (2), 251-254.

(26) Benetti, E. M.; Kang, C. J.; Mandal, J.; Divandari, M.; Spencer, N. D., Modulation of Surface-Initiated ATRP by Confinement: Mechanism and Applications. Macromolecules 2017, 50 (15), 5711-5718.

(27) Kang, C. J.; Ramakrishna, S. N.; Nelson, A.; Cremmel, C. V. M.; Stein, H. V.; Spencer, N. D.; Isa, L.; Benetti, E. M., Ultrathin, freestanding, stimuli-responsive, porous membranes from polymer hydrogel-brushes. Nanoscale 2015, 7 (30), 13017-13025. (28) Milner, S. T.; Witten, T. A.; Cates, M. E., Theory of the Grafted Polymer Brush. Macromolecules 1988, 21 (8), 2610-2619. (29) Chang, Y.; Shih, Y. J.; Lai, C. J.; Kung, H. H.; Jiang, S. Y., Blood-Inert Surfaces via Ion-Pair Anchoring of Zwitterionic Copolymer Brushes in Human Whole Blood. Adv. Funct. Mater. 2013, 23 (9), 1100-1110.

(30) Zhang, Z.; Chao, T.; Chen, S. F.; Jiang, S. Y., Superlow fouling sulfobetaine and carboxybetaine polymers on glass slides. Langmuir 2006, 22 (24), 10072-10077.

(31) Jiang, S. Y.; Cao, Z. Q., Ultralow-Fouling, Functionalizable, and Hydrolyzable Zwitterionic Materials and Their Derivatives for Biological Applications. Adv. Mater. 2010, 22 (9), 920-932. (32) Feng, W.; Brash, J. L.; Zhu, S. P., Non-biofouling materials prepared by atom transfer radical polymerization grafting of 2- 
methacryloloxyethyl phosphorylcholine: Separate effects of graft density and chain length on protein repulsion. Biomaterials

2006, 27 (6), 847-855.

(33) Luo, B. H.; Carman, C. V.; Springer, T. A., Structural basis of integrin regulation and signaling. Annu. Rev. Immunol. 2007, 25, 619-647.

(34) Gumbiner, B. M., Regulation of cadherin-mediated adhesion in morphogenesis. Nat. Rev. Mol. Cell Bio. 2005, 6 (8), 622-634.

(35) Marcus, R. E., Effect of Low Oxygen Concentration on Growth, Glycolysis, and Sulfate Incorporation by Articular Chondrocytes in Monolayer Culture. Arthritis Rheum. 1973, 16 (5), 646-656.

(36) Kim, J. Y.; Lee, B. S.; Choi, J.; Kim, B. J.; Choi, J. Y.; Kang, S. M.; Yang, S. H.; Choi, I. S., Cytocompatible Polymer Grafting from Individual Living Cells by Atom-Transfer Radical

Polymerization. Angew. Chem. Int. Edit. 2016, 55 (49), 15306-

15309.

(37) Broach, J. R.; Jones, E. W.; Pringle, J. R., The Molecular and Cellular Biology of the Yeast Saccharomyces, Cold Spring Harbor Laboratory Press, Cold Spring Harbor, NY, 1991. 
Table of content graphics:

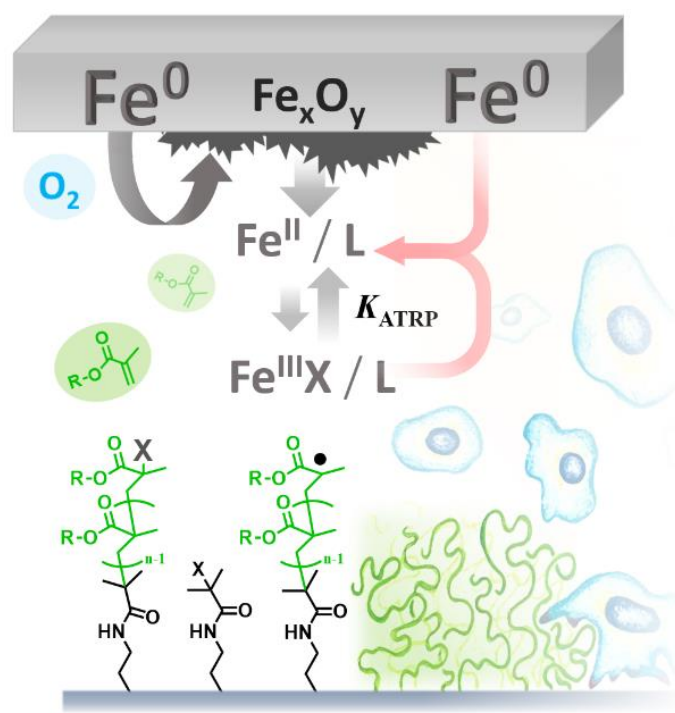

